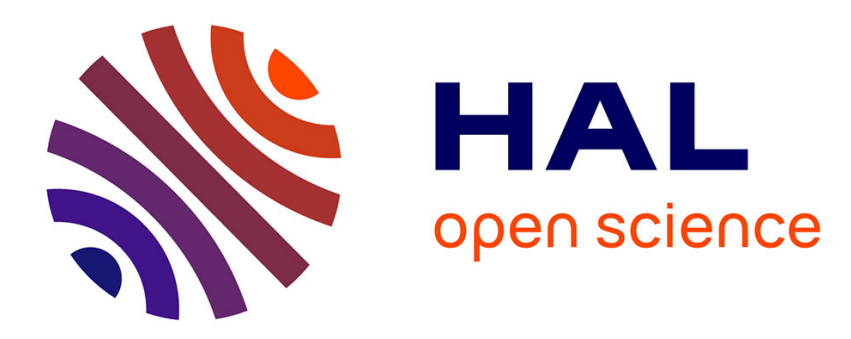

\title{
Microstructure and fracture behaviour of SiCp/Al-2618 metal matrix composite
}

\author{
Y. Zong, B. Derby
}

\section{To cite this version:}

Y. Zong, B. Derby. Microstructure and fracture behaviour of SiCp/Al-2618 metal matrix composite. Journal de Physique IV Proceedings, 1993, 03 (C7), pp.C7-1861-C7-1866. 10.1051/jp4:19937298 . jpa-00251941

\section{HAL Id: jpa-00251941 https://hal.science/jpa-00251941}

Submitted on 1 Jan 1993

HAL is a multi-disciplinary open access archive for the deposit and dissemination of scientific research documents, whether they are published or not. The documents may come from teaching and research institutions in France or abroad, or from public or private research centers.
L'archive ouverte pluridisciplinaire HAL, est destinée au dépôt et à la diffusion de documents scientifiques de niveau recherche, publiés ou non, émanant des établissements d'enseignement et de recherche français ou étrangers, des laboratoires publics ou privés. 


\title{
Microstructure and fracture behaviour of SiCp/Al-2618 metal matrix composite
}

\author{
Y. ZONG and B. DERBY \\ Oxford Centre for Advanced Materials and Composites, Department of Materials, University of Oxford, \\ Parks Road, Oxford OX1 3PH, U.K.
}

\begin{abstract}
Spray formed $\mathrm{SiC}$ reinforced $2618 \mathrm{Al}$ alloy has potential as an elevated temperature MMC, and its fracture behaviour and mechanical properties have been investigated. SEM observation of matched fracture surfaces and cross-sectional observation of fractured specimens indicate that the composite at T6 temper fractures mainly through $\mathrm{SiC}$ particle cracking and that this could begin at very early stages of strain, smaller than $1 \%$. Damage evolution is measured in terms of modulus reduction tests and compared with metallographic observations of particle fracture beneath the fracture surface. Modulus reduction and mechanical property tests have been carried out over a range of temperatures up to $220^{\circ} \mathrm{C}$.
\end{abstract}

\section{INTRODUCTION}

Reductions in material density or increases in stiffness, yield strength and ultimate tensile strength can be directly translated to reductions in structural weight. This has led the aerospace materials industry to develop and examine new composite materials with combinations of low density, improved stiffness and high strength as attractive alternatives to existing high-strength $\mathrm{Al}$-alloys and $\mathrm{Ti}$-alloys (1). SiC particle reinforced Al-alloys matrix composites are of interest because of their particular advantages of easy manufacturing and processing compared with the other MMCs.

Some possible applications of SiCp/Al MMCs require high temperature strength, stiffness and mechanical performance, for example brake callipers, conrods and pistons in automotive applications. $\mathrm{SiCp} / \mathrm{Al}-2618$ composite has potential as an elevated temperature MMC because of its matrix composition. Spray deposition to produce MMCs is particularly advantageous for 2618 alloys as it results in the refinement of the $\mathrm{Fe}$ and Ni containing dispersoids and is very efficient (2). Also, this MMC has a lower potential cost than the higher strength aluminium-lithium alloys.

The poor ductility and fracture behaviour of MMCs are the chief limits to their application especially, their deterioration during mechanical and thermal strain (3-4). There have been previous investigations of the mechanical properties of SiCp/Al-2618 composite (5). Here, mechanical properties and fracture behaviour of MMCs with different heat treatments will be studied over a range of temperatures up to 220 ${ }^{\circ} \mathrm{C}$. However, damage evolution of the composite is the essential topic of this research and measurements of elastic modulus reduction will be related with the microstructural changes observed experimentally.

\section{EXPERIMENTAL}

The experimental materials were supplied by Alcan International Ltd. and were spray formed then hot extruded. The composite was a nominal 15\% volume fraction of SiC particle reinforced Al-2618 (Al$2.5 \% \mathrm{Cu}-1.5 \% \mathrm{Mg}-1.1 \% \mathrm{Ni}-1.1 \% \mathrm{Fe}$ ) matrix MMC. A monolithic Al-2618 alloy which was used for 
comparison was produced using the same procedures and contains a maximum of $0.5 \% \mathrm{SiC}$ particles. A $530^{\circ} \mathrm{C} / 2 \mathrm{~h}$ solution treatment followed by an ice-water quenched was carried out before the materials were machined into cylindrical tensile dumb-bell specimens of $5 \mathrm{~mm}$ diameter and $40 \mathrm{~mm}$ gauge length. Some specimens were then reheated to $530^{\circ} \mathrm{C}$ for 2 hours and then furnace cooled, others retained in the solution treated condition, another group was aged at $140{ }^{\circ} \mathrm{C}$ for 2 hours and the final specimens were aged at $200^{\circ} \mathrm{C}$ for 20 hours. These are hereafter referred to as annealed, quenched, under-aged and T6 (peak aged) specimens respectively.

The microstructures of the composite before and after tensile testing were examined on a Quantimet 900 optical microscope which is equipped with a computer-controlled image analysis system to determine the volume fraction, number and geometric features of selected features. The broken SiC particles were distinguished from all SiC particles on screen manually. A double cantilever loading geometry was used to produce tensile fracture surfaces for SEM observation in order to find matched positions on the fracture surfaces more easily.

All tensile tests were carried out on a Mays servo-electric testing machine model DM30 at a strain rate of $3.5 \times 10^{-5} \mathrm{Sec}^{-1}$. Elastic moduli were measured throughout the tests by repeatedly unloading and reloading after different amounts of strain, using an extensometer and two type FLA-3-23 strain gauges on both sides of each specimen centre at room temperature and type ZFLA-3 gauges at elevated temperatures. The modulus data were derived from the extensometer's measurements corrected by the first strain gauges' measurement because of the limited measurable strain of the strain gauges.

\section{RESULTS AND DISCUSSION}

\subsection{Microstructure Observation}

Metallographic samples of both materials and various tempers were prepared in the longitudinal section by spark erosion to avoid extra mechanical damage and then carefully polished. Observations of composite samples show that the SiC particles are not very evenly distributed but occur in many clusters. It is commonly argued that the $\mathrm{SiC}$ particle distribution is important because microcrack nucleation and coalescence in the composite are highly dependent on local particle volume fractions rather than on the average distribution in the whole material (4-7). However, there is little in the composite literature about the representation of particle distribution and relationships between it and fracture properties. Fig.1 presents the local SiC volume fraction distribution of the composite from 108 measurements distributed regularly over the complete specimen surface of $60 \mathrm{~mm}^{2}$, each measured area is a $0.1 \times 0.083 \mathrm{~mm}$ rectangle. The local $\mathrm{SiC}$ volume fraction can be as high as $32 \%$

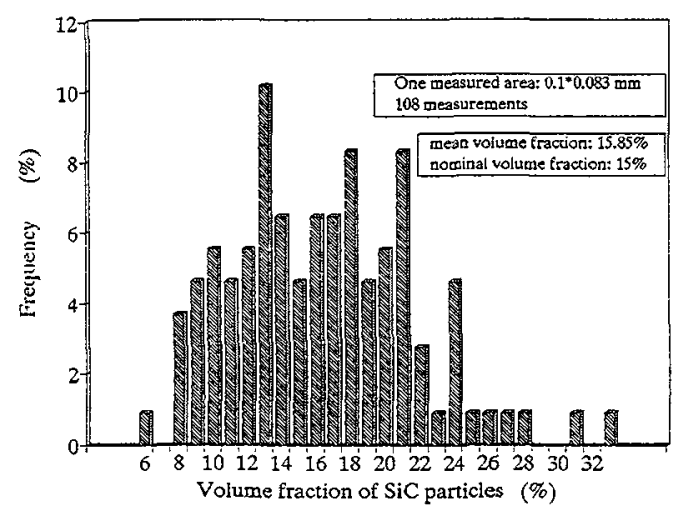

Fig. 1 Distribution of local volume fractions in a spray formed SiCp/Al-2618 MMC

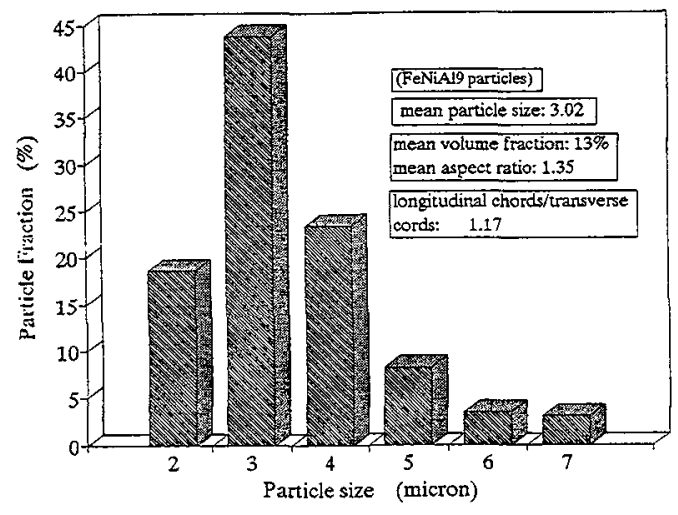

Fig.2 Distribution of intermetallic dispersoid size in the matrix of a SiCp/Al-2618 MMC

but most are between $10-20 \%$ in nearly equal frequency. Note that the local particle volume fraction distribution is dependent on the size of the measured local area. SiC particle features were also investigated and the size of $85 \%$ of the $\mathrm{SiC}$ particles is between 6 and $14 \mu \mathrm{m}$ but some can be as large as $26 \mu \mathrm{m}$. The mean aspect ratio of the $\mathrm{SiC}$ particles is 1.8 and the mean ratio of each particle's maximum 
longitudinal /maximum transverse dimension is 1.04 . Extrusion does not affect SiC distribution very much. As well as the SiC particles in the composite, there are many intermetallic dispersoids of FeNiAlg in the matrix and their size distribution is presented in Fig.2. The FeNiAlg particle measurements were carried out on a monolithic alloy of T6 temper but it is expected to be the same in the composite matrix. After observation of these features, all samples were etched with an aqueous solution containing $2 \% \mathrm{HF}$, $2 \% \mathrm{HCl}$ and $3 \% \mathrm{HNO}_{3}$ for 50 s. to reveal grain sizes of the composite matrix and monolithic alloy. It was found that the average grain size of the composite matrix at T6 temper is about $20 \mu \mathrm{m}$ whereas the monolithic alloy was about $40 \mu \mathrm{m}$ in the same condition. The decreased grain size which is probably controlled by the SiC particle's pinning effect, is one of the reasons why the composite has a higher strength than the monolithic alloy.

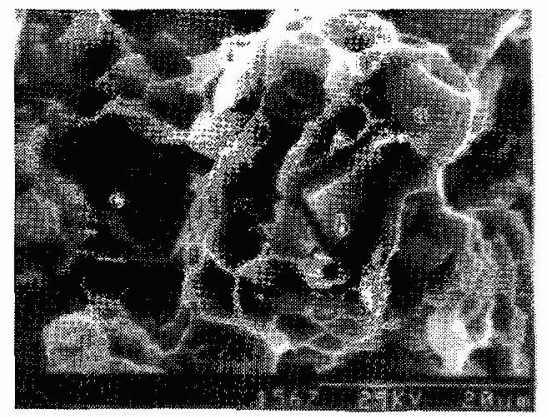

(a)

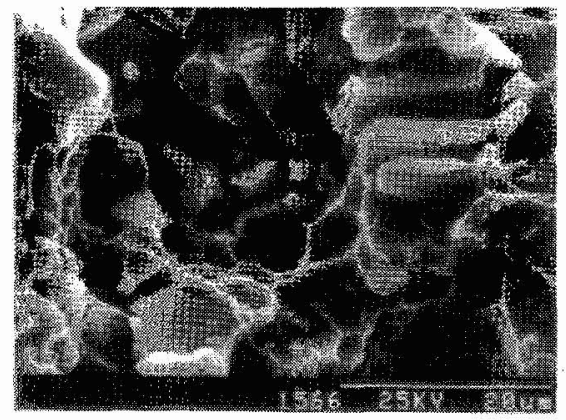

(b)

Fig.3 (a) SEM image of the fracture surface of the T6 composite. (b) Matched fracture surface of (a).

3.2 Observation of the Fracture Surface

After tensile fracture, both surfaces of each broken specimen was examined by SEM. The fracture surface of the composite showed typical ductile fracture features with big dimples corresponding to $\mathrm{SiC}$ particles and many other small dimples in the matrix. Fig. 3 shows matched fracture surfaces of the T6 composite, broken particle pieces on both surfaces can be seen for every $\mathrm{SiC}$ particle. Thus, the composite in $\mathrm{T} 6$ temper fractures through the cracking of $\mathrm{SiC}$ particles. Matched fracture surface observation of the annealed composite showed that the majority of the SiC particles had fractured but intensive distortion of big dimples by much matrix deformation revealed the presence of some $\mathrm{SiC}$ particles decohesion within the matrix. Limited fracture surface observation of the monolithic alloy $(0.5 \% \mathrm{SiC})$ did not find any $\mathrm{SiC}$ particles on the surfaces but fine dimples with sharp circular edges were seen with a spherical dispersoid of FeNiAlg within most dimples. Observations of longitudinal sections of fractured alloy samples showed that the few $\mathrm{SiC}$ particles seen beneath the fracture surface had not cracked, though many FeNiAls particles around them were cracked.

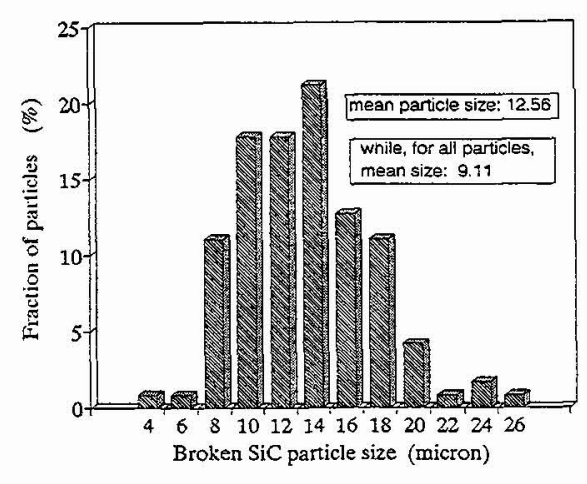

Fig.4 Distribution of broken SiC particle size in the T6 composite after tensile fracture

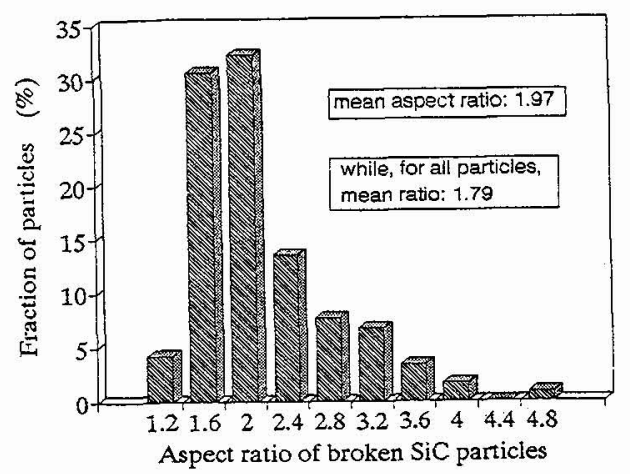

Fig. 5 Distribution of aspect ratio of broken $\mathrm{SiC}$ particles in the $\mathrm{T} 6$ composite after fracture 
3.3 Characteristics of Broken SiC Particles

A fractured T6 composite specimen, tested in tension, was sectioned by spark erosion along its longitudinal axis. The broken SiC particles beneath the fracture surface within the deformed area were measured to reveal their characteristics. Fig. 4 shows that the broken SiC particle's mean size is $12.6 \mu \mathrm{m}$ which is larger than the average size of all SiC particles in the composite, $9.1 \mu \mathrm{m}$. It was also found, (Fig.5), that the mean aspect ratio of broken SiC particles of 2.0 is larger than that of all $\mathrm{SiC}$ particles, 1.8. Moreover, image analysis results showed that the average longitudinal /transverse dimension of the broken SiC particles, 1.14, is larger than that of all SiC particles, 1.04, so that $\mathrm{SiC}$ particles with a large aspect ratio along the tensile direction tend to be easily cracked under strain.

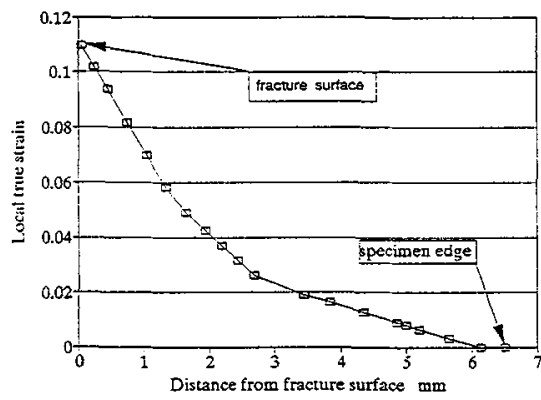

Fig.6 Local plastic strains in a fractured tensile specimen of the T6 composite as a function of distance from the fracture surface

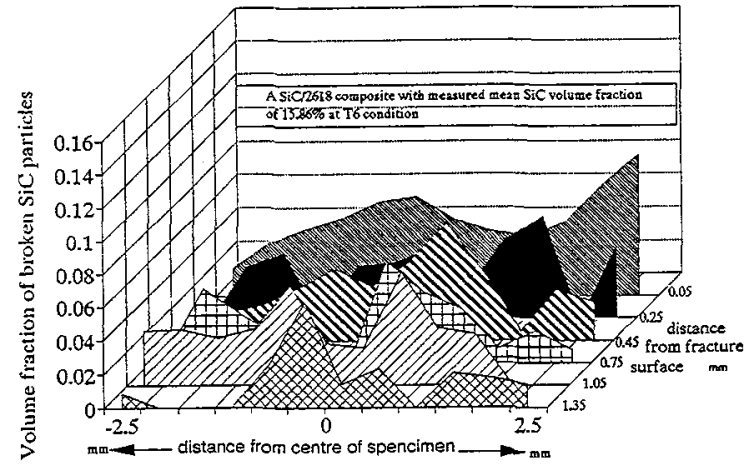

Fig.7 Local fractions of broken $\mathrm{SiC}$ volume in different positions of the fractured tensile specimen of Fig. 6

3.4 Microstructural Damage Evolution

There have been some reports of damage evolution in $\mathrm{SiC}(\mathrm{p}) / \mathrm{Al}-7 \mathrm{xxx}$ and $\mathrm{SiC}(\mathrm{p}) / \mathrm{Al}-6061 \mathrm{MMCs}$ by investigating the microstructure but only specimen surfaces were used for the observations (6-7). It is obvious that the stress state of the specimen surface which has a plane stress condition is very different from that of the interior of the specimen which is closer to a plane strain condition during tensile testing therefore, it will be more reliable if the microstructural observation could be carried out on the whole section of the specimens. However, it is impossible to observe the microstructure in the specimen's section during a tensile test so an attempt was made to observe the cross-section of the specimen, to count microstructural features with respect to distances from the fracture surface, after tensile fracture. Fortunately, the composite does not neck much locally. The local true strain can be determined by measuring the local specimen diameter $\mathrm{D}$ with $\mathcal{E}_{\mathrm{T}}=$ $-\ln \left(\mathrm{D} / \mathrm{D}_{0}\right)$ where $\varepsilon_{\mathrm{T}}$ is the true strain and $\mathrm{D}_{0}$ the diameter of the specimen before tensile testing. Fig.6

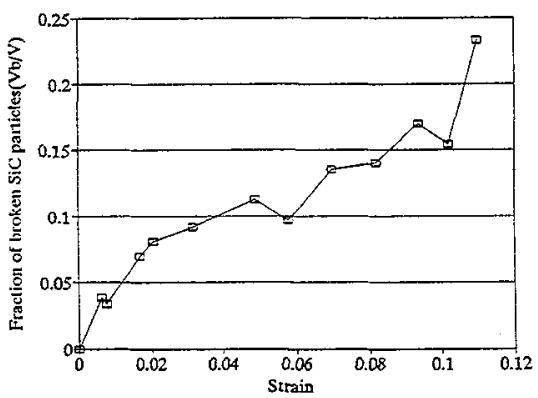

Fig. 8 The increase in volume fraction of broken $\mathrm{SiC}$ particles( $\mathrm{Vb})$ over that of all $\mathrm{SiC}$ particles $(\mathrm{V})$ as a function of plastic strain for the T6 composite

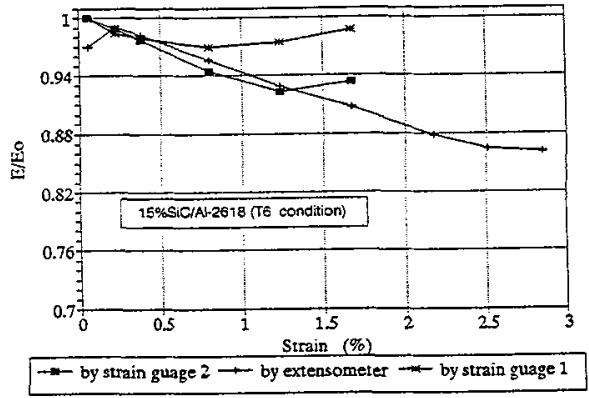

Fig.9 The elastic modulus reduction as a function of plastic strain for the T6 composite at $25^{\circ} \mathrm{C}$ 
shows the local true strain of the specimen as a function of distances from the fracture surface for a T6 composite specimen. The microstructure of this specimen was examined for broken SiC particles and the results are displayed in Fig.7. Fig. 8 shows the average volume fractions of broken SiC particles as a function of the distances from the fracture surface. In Fig.8, damage evolution with strain is represented by the increasing fraction of broken $\mathrm{SiC}$ particles throughout the specimen and not just along the specimen surface.

3.5 Damage Evolution Measured by Elastic Modulus Reduction

Fig.9 shows the elastic modulus reduction with strain during tensile testing of a T6 composite specimen. The use of the extensometer for this measurement is quite good except near the beginning of the test. Therefore, the initial elastic modulus, $\mathrm{E}_{0}$ ( plastic strain is approximately zero ) was determined by the average value of two strain gauge measurements and then, all further data used the extensometer measurement modified by $E_{0}$. Fig. 10, coming from combining Fig.9 with Fig.8, shows that the measurement of the composite modulus decreasing with strain is consistent well with observations of microstructural damage of broken $\mathrm{SiC}$ particles. Thus, elastic modulus reduction can be used to represent microstructural damage of the composite though a more exact relationship needs a suitable model because not only the cracking of SiC particles but also the voids nucleation and growth in the matrix may also contribute the modulus reduction.

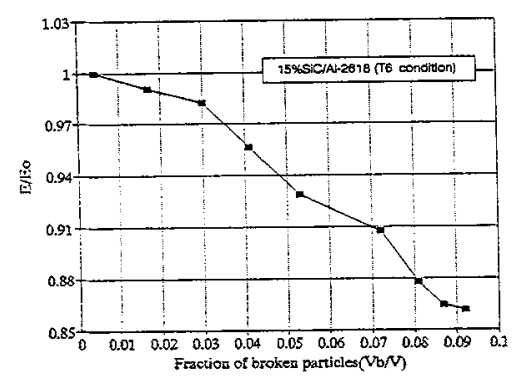

Fig.10 The modulus reduction plotted against the fraction of broken $\mathrm{SiC}$ particles for the T6 composite

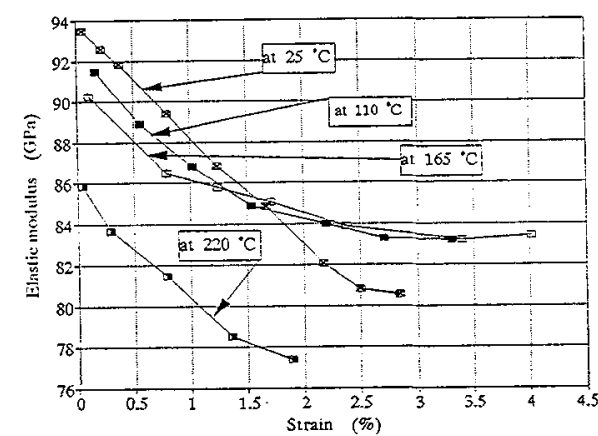

Fig.11 Damage evolution(elastic modulus reduction) of a SiCp/Al-2618 composite of $\mathrm{T} 6$ temper as a function of tensile strain over a range of temperatures up to $220^{\circ} \mathrm{C}$

\subsection{Damage Evolution During High Temperature Deformation}

Elastic moduli of the T6 composite as a function of tensile strain as measured at various temperatures are presented in Fig. 11. From Fig.11, it can be seen that the modulus decreases with strain at all temperatures but it seems that the composite deteriorates abruptly at temperatures over about $200^{\circ} \mathrm{C}$. It should be noticed that elastic modulus of the composite decreases with increasing test temperature from $25^{\circ} \mathrm{C}$ to $165^{\circ} \mathrm{C}$ when the plastic strain is less than $1.5 \%$ however, when the plastic strain is over $1.5 \%$ the modulus does not

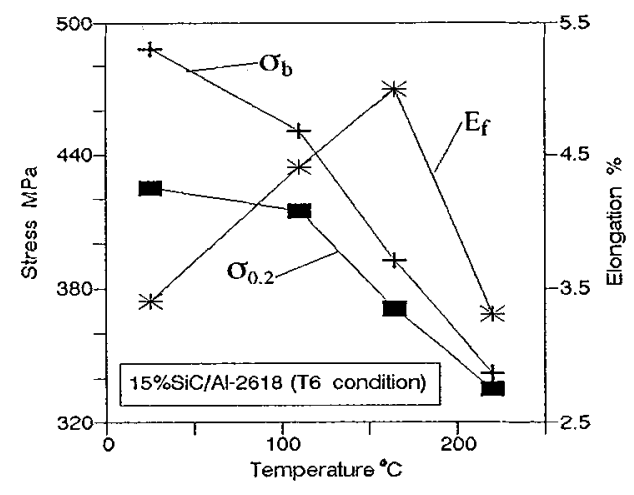

Fig.12 Tensile test results of the T6 composite over a range of temperatures up to $220^{\circ} \mathrm{C}$ 
decrease as much at elevated temperatures as at room temperature and the modulus at $2 \%$ strain is actually larger at higher temperatures. At high temperatures the matrix may be softer and thus, is not able to transfer much load to the SiC particles so that after a large amount of strain the composite may possess a smaller fraction of broken SiC particles at elevated temperatures than at room temperature. This hypothesis has get to be tested with microstructural observations. Fig.12 is the tensile test results of the

T6 composite over a range of temperatures up to $220{ }^{\circ} \mathrm{C}$. The $0.2 \%$ proof $\operatorname{stress}\left(\sigma_{0.2}\right)$ and failure

strength $\left(\sigma_{\mathrm{b}}\right)$ of the composite go down with increasing the test temperature as expected but the final elongation (Ef) goes up with temperature in the beginning and then drops suddenly when the temperature is over about $200^{\circ} \mathrm{C}$.

\section{SUMMARY}

The microstructure, fracture surface observation and damage evolution of a SiCp/Al-2618 MMCs have been carried out at several temperatures with different tempers. The results so far might be summarised below:

*. The distribution of local $\mathrm{SiC}$ particle dimensions and volume fractions within the composite has been measured. Observations of broken $\mathrm{SiC}$ particles indicate that large SiC particles with high aspect ratios especially aligned along the tensile direction tend to be cracked easily.

*. The use of a single fractured MMC specimen allows us to evaluate the fraction and nature of broken $\mathrm{SiC}$ particles as a function of strain.

*. Elastic modulus reduction of the composite when strained shows a good correspondence to the percentage of broken $\mathrm{SiC}$ particles.

*. At elevated temperatures, modulus reduction in the T6 composite specimen is less severe as a function of strain up to about $200^{\circ} \mathrm{C}$. Above this temperature severe modulus reduction is found.

*. The composite with T6 temper shows a final elongation increasing with temperature in the beginning and then dropping abruptly when temperature is over about $200^{\circ} \mathrm{C}$.

\section{Acknowledgements}

The authors would like to acknowledge Alcan International Ltd. for supplying the materials and the SERC for support under grant GR/F87660. Y. ZONG would like to express many thanks to Dr P. Mummery for much help in the experiments and to the Chinese Education Committee and the British council for a Cooperation Scholarship.

\section{REFERENCES}

1). T S Srivatsan, I A Ibrahim, F A Mohamed and E J Lavernia, J. Mater. Sci., Vol. 26, p5965, 1991.

2). M Cupta, F A Mohamde and D J Laveria, Mater. Manufact. Proc., Vol.6, No.2, p165, 1990.

3). P Mummery and B Derby, Materials Science and Engineering, Vol. 135A, p221, 1991.

4). B Derby, Proceedings of the 12th Risø International Symposium on Materials Science, edited by N Hansen et al.,

Roskilde, Denmark, p31, 1991.

5). J. LLorca, A. Martin, J. Ruiz and M. Elices, MET. TRAN., A, in review, 1993.

6). J J Lewandowski, C Liu and W H Hunt Jr., Mat. Sci. Eng., A, 107(1989)241.

7). D J Lloyd, Acta Metall. Mater., Vol.39, p59, 1991. 